\title{
THE RELATION BETWEEN PURE AND APPLIED BIOLOGY
}

BY

Professor E. B. POULTON, M.A., D.Sc., LL.D., F.R.S.

REPRINTED FROM

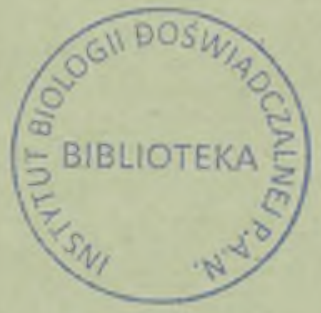

THE ANNALS OF APPLIED BIOLOGY

VOL. XI, NOS. 3 \& 4, OCTOBER 1924

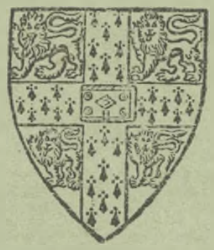

CAMBRIDGE

AT THE UNIVERSITY PRESS

PRINTED IN GREAT BHITAIN

rcin.org.pl 
rcin.org.pl 
[From the ANNALS OF APPLIED BIOLOGY, Vol. XI, Nos. 3 \& 4, October, 1924.]

[All rights reserved.]

THE RELATION BETWEEN PURE AND APPLIED BIOLOGY

By Professor E. B. POULTON, M.A., D.Sc., LL.D., F.R.S.

BEING THE ADDRESS OF THE RETIRING PRESIDENT OF THE ASSOCIATION, DELIVERED JANUARY 18TH, 1924.

Ат the end of my term of office it is a pleasing duty to thank the officers of the Association who have made my work so light, the readers of papers from whom we have learned so much of interest and importance, and those who have contributed to the discussions which have given an added vitality to our meetings. It has been most inspiring to see such numbers of students coming together month after month to listen and I have no doubt to criticise; and this in the early afternoon, a time which for many is held to be sacred to the cult of the open air.

I have all through looked forward to the pleasure and privilegc of thanking those who have made my term of office so easy and so interesting, and of expressing the confident hope that the same kind help would be extended to my successor. But when it comes to a Presidential address, that is a different matter. An address if required is a chief, probably the chief, responsibility of the position. I am a very busy man and the work seems to increase as I become older. Furthermore I have had to deliver many addresses. It is a good thing that, from time to time, a man should be induced to look at his subject from a new point of view, and I do not agree with an opinion recently expressed by a senior member of a scientific society, as the anniversary meeting was approaching - that "the whole thing is a waste of time: the President doesn't want to give an address and nobody wants to listen to it!"

A Presidential address is I believe a good thing, but a man should not be expected to give many. Suitable subjects are not very numerous, and, if treated seriously, all of them demand much time and thought. A man owes it to himself, or as I prefer to say, to those who look to him for guidance, not to spend too much time in the preparation of addresses on the more general aspects of his subject. Therefore, when honoured with the invitation, I asked whether an address was necessary and received the assurance that it was not required. I bope that this will 


\section{The Relation between Pure and Applied Biology}

continue to be your tradition. We have many scientific societies in this country and your Presidents will often be men who have previously served elsewhere and some of them may find a real difficulty in again accepting a position which carries this responsibility.

In spite of the assurance given to me I am delivering a brief address in compliance with the wishes of our late Secretary, Dr W. B. Brierley, to whose efficiency and energy we owe so much. He was so persuasive that I felt compelled to compromise and agree to do as he wished, not however twice, but at the end of my term of office. It is the kind of thing one undertakes to do a year-and-a-half ahead-a distant future when the pressure of work will surely be relieved! That is the dream, but presently comes the awakening. It seems to be a law of human nature that as the fatal day approaches and time for thought is urgently required, work of all kinds, work which cannot be put off, steadily accumulates. Therefore today I can only offer you a spoken and not a written address. I hope however that this is not all loss, and that you will agree that speech face to face has some advantages over the more rounded written sentences more or less hidden behind a paper screen.

The revenge I might have taken is denied me. If Dr Brierley had remained in office I might perhaps have followed the example of an eminent President of a scientific society and have written a very polite letter to the Secretary asking him to give me his kind help by preparing notes on the recent advances in our science, and when the notes were received, I might have acted as he did and returned them to the Secretary with the most grateful thanks but asking if he would add to my indebtedness by throwing them into the form of an address!

It is of interest to compare for a moment Applied Biology with Applied Physics and Chemistry. Our friends sometimes take a rather superior tone in comparing their sciences with ours. I remember a Physicist friend who, when it was maintained that it would be useful to have some common term to include Physics and Chemistry just as Biology includes both Zoology and Botany, replied at once "Oh! but we have such a term-Science!" But there is reason to fear that the share in science which my friend allotted to Chemistry was very different from that which he claimed for his own subject. It was a haughty Physicist who defined Chemistry as "The dirty part of Physics and the clean part of Biology!"

In Applied Science, however, Biology has a great advantage over Physics and Chemistry-an advantage which is especially great in the 
department of learning with which this Association deals. Every problem concerned with living beings compels the student to search in many directions, to seek all possible help in the widest field, and generally to invoke the assistance of the haughty sciences themselves. The simplest living being is infinitely complex and enters into an infinitely complex indirect relationship with the world around it. The attempt to unravel a part of this entangled web is not only broadening and strengthening to the intellectual faculties but also to the social side of human nature. On other occasions I have dwelt upon the broadening influence of an intelligently directed specialisation, but this aspect is so often neglected that I do not hesitate to speak of it again. The infinitely complex problem set before the student of Applied Biology compels him to seek help from other specialists. His own work shows him the uselessness of an opinion founded on superficial study, and he realises that the rapid glance of one who knows is generally worth far more than a prolonged examination by one who is without an intimate knowledge of the subject. He is thus led to pursue to the uttermost his own researches in his own part of the great field without any inclination to encroach on the sections where others are at work-to give help and to receive help, to take a keen and friendly interest in the investigations going on around him and to welcome the same interest in his own.

Specialisation pursued in this spirit, so far from being narrow and narrowing, is broadening as an education and broadening as a social force; for it leads to mutual appreciation instead of mutual jealousy. It is a spirit very different from that of a not distant past symbolised by Professor Ptthmllnsprts in The Water-Babies. Only recently I have come to realise, thanks to Stephen Paget in I have reason to believe, that the weird name is "Put them all in spirits" with the vowels left out! Well, you remember that Professor Ptthmllnsprts was said to be like a cock-robin, because "when anyone else found a curious worm, he would hop round them, and peck them, and set up his tail, and bristle up his feathers, just as a cock-robin would; and declare that he found the worm first; and that it was his worm; and, if not, that then it was not a worm at all."

But even in those years of fierce rivalries which seem so far off and are really so near, we find the highest of all examples of mutual sympathy and appreciation in the two great men who, on opposite sides of the world, hit upon the same discovery. On July 1, 1908, the Linnean Society celebrated the fiftieth anniversary of the announcement of the theory of natural selection in the Darwin-Wallace Essay. Darwin and 


\section{The Relation between Pure and Applied Biology}

Sir Charles Lyell had been dead many years but the other chief actors, Alfred Russel Wallace and Sir Joseph Hooker, were present and spoke to us. And the essential message conveyed by Wallace's speech on that great occasion was a protest against the too great credit which he had been given for his part in the discovery. Of Darwin's part in it he said"If the persuasion of his friends had prevailed with him, and he had published his theory, after 10 years'-15 years'-or even 18 years' elaboration of it - $I$ should have had no part in it whatever, and he would have been at once recognised, and should be ever recognised, as the sole and undisputed discoverer and patient investigator of the great law of 'Natural Selection' in all its far-reaching consequences."

It may be fairly claimed that the grip of the profession is less constraining in Applied Biology than in Applied Physics and Chemistry. The notice "No road" is far less likely to be displayed over against some fascinating side-path, because in Biology a side-path so often leads to the goal.

Leaving the application on one side for the moment, it is well to realise the motive which impels to research. When you get down to bedrock you will find that the true inducement is the gratification of the instinct of discovery, indulgence, in fact, in a glorified curiosity. I remember the amusing words in which this conclusion was enforced by Michael Foster. "It was by curiosity" he said "that our first parents lost the Garden of Eden, but by transmitting to us that same curiosity they built for us a golden bridge by which we may re-enter Paradise." And surely the glorious moment when scientific curiosity is satisfied takes us into an earthly Paradise if anything can.

The true motive-power of research is stated by Darwin in a letter to Henslow who had maintained that "However delightful any scientific pursuit may be, yet, if it should be wholly unapplied, it is of no more use than building castles in the air." Darwin in reply pointed to the practical uses which came later but could never have come except with the aid of scientific work conducted solely for its own sake. And he continued: "For myself I would, however, take higher ground, for I believe there exists, and I feel within me, an instinct for truth, or knowledge or discovery, of something of the same nature as the instinct of virtue, and that our having such an instinct is reason enough for scientific researches without any practical results ever ensuing from them."1

I do not think that Darwin's argument needs enforcing at the present day, for I believe that everyone will agree with it. You will observe that

\footnotetext{
1 More Letters, I, 61.
} 
there is nothing in his words to discourage applied science, provided that its problems are approached in the spirit of which he wrote. And the success which has attended these enquiries is in itself sufficient evidence that they have been undertaken in this spirit. The immense increase in our knowledge of detailed life-histories and the bionomic relations of animals and plants which we owe to the researches in Economic Biology at Washington, in Hawaii, and in this country at Rothamsted and under the guidance of the Imperial Bureau of Entomology and that of Mycology - all this has meant the love of knowledge for its own sake and, without this inspiration, could not have been achieved. If immediate practical benefits result so much the better; if not, the outcome is still as it is in other scientific researches, increase in the mass of human knowledge, out of which practical benefits are certain to come in the end.

Any man who has had much to do with scientific students will have realised that many of them-a large proportion happily - are full of scientific curiosity - the love and the longing for discovery-and that they are eager to catch at any suggestion made by one older and more experienced. The suggestions for research in Economic Biology are everywhere around us appealing to the same spirit as that in which the young student begins his first investigation for the love and the glory of discovery alone. If they are not accepted in this spirit they had better not be undertaken at all. But I have no fears. As I have already indicated, the results attained speak for themselves, proclaiming that the work has been done in the spirit of all scientific enquiry, in the intense desire to find out, to know why - the motive cause of all discovery and advance.

Before I conclude there are a few general considerations which I should wish to bring before those of you who are looking forward to a life devoted to the problems of Economic Biology.

The Differences between Island and Continental Areas. The attempt to deal with some economic pest is far less difficult on an island than on the mainland. On the smaller area, with its far simpler web of organic life, there is a good chance of exterminating the evil altogether or of reducing it to comparative harmlessness by the introduction of its natural enemies. Of these some, also attacking other species, may find in the limited fauna little or no food except that provided by the injurious species and will then threaten it, and finally themselves, with extermination. Such a result is far less likely on a continental area, and if it should occur, will only be local and the pest can later on re-invade the locality from the surrounding districts. Again, the simpler environment, 


\section{The Relation between Pure and Applied Biology}

inorganic as well as organic, may itself solve or help to solve the problem without any human effort. Storms and other climatic disturbances will tend to produce far greater destruction of life on islands. In a recent attempt to investigate the invasion of the Fijian Islands, and to a less extent other Pacific groups, by certain butterflies and the changes which have taken place in the new home, I have been much struck with the fact that the only evidences of evolution are very modern and superficial and that nothing older has been preserved. There is not only the possibility of hurricanes of exceptional force but of an enemy such as a bird increasing in numbers and entirely destroying some species which it normally only keeps in check. Or again an intruder may itself increase progressively and destroy its own food-plant. All such effects, probable enough on islands, are far less likely to happen over large continental areas.

Unchecked Variation. Whatever the problem before the scientific enquirer he will do well to keep a sharp look out for incidental results of the deepest interest which may often be gained by the way without interrupting the main current of his work or may often-times divert it into a more fruitful channel. The exciting subject of variation is one upon which the Economic Biologist is especially likely to throw light. Under ordinary conditions, with reproduction so far balanced by extermination that the average numbers of a species remain constant, there is reason to believe that variation is held in check by selection. But now and then a time will come-a time in which the help of the Economic Biologist is likely to be required-when a species gets the better of the forces which normally hold it in check, and increases beyond all bounds. The proportionate amount of variation in these temporarily well-nigh selection-free periods is a fascinating subject for study.

The Ebb and Flow of Evolution. The Economic Biologist, like every student of living nature, is sure to consider the bearing of his work upon evolutionary theories and it is therefore well to direct attention to an aspect of evolution which is sometimes neglected. Evolution does not take and probably has never taken a road that leads continuously upward, but one of endless ups and downs, only to be recognised as an advance when averaged over a considerable distance. The upward movement of a single undulation, to be followed at once by an equal or perhaps an even greater descent, is liable to be mistaken for true evolutionary progress. The possibility of such an erroneous interpretation has been forced upon me in studying the changes in the colours and patterns of insects. Colours and patterns were of course evolved from a previous 
condition of insect life in which they did not exist, and it is tempting to look upon the changes which a pattern undergoes in a series of allied races as part of the great onward movement of evolutionary history. But further investigation shows that the patterns, once formed, have been subject to constant fluctuation, increasing complexity succeeded by increasing simplicity and this again by complexity in endless succession. I do not doubt that the same ebb and flow is true of other aspects of organic nature where it is less easily detected and therefore all the more likely to suggest a fascinating but erroneous interpretation.
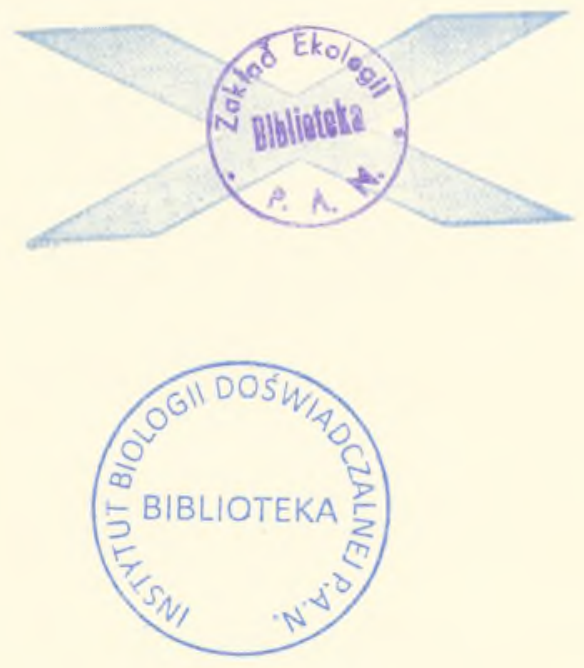
rcin.org.pl 
rcin.org.pl 
rcin.org.pl 